\title{
Swimming: Effects on Stress Urinary Incontinence and the Expression of Nerve Growth Factor in Rats Following Transabdominal Urethrolysis
}

\author{
Il Gyu Ko, Sung Eun Kim, Bo Kyun Kim, Mal Soon Shin, Chang Ju Kim, Sung Jin Yim¹, Yu Jeong Bang², \\ In $\mathrm{Ho} \mathrm{Choi}^{3}$, Khae Hawn Kim ${ }^{3}$ \\ Department of Physiology, Kyung Hee University School of Medicine, Seoul; \\ ${ }^{1}$ Department of Urology, Kangbuk Samsung Hospital, Sungkyunkwan University School of Medicine, Seoul; \\ ${ }^{2}$ Gachon University of Medicine and Science, Incheon; \\ ${ }^{3}$ Department of Urology, Gachon University Gil Hospital, Gachon University of Medicine and Science, Incheon, Korea
}

\begin{abstract}
Purpose: Stress urinary incontinence (SUI) commonly occurs in women, and it has an enormous impact on quality of life. Surgery, drugs, and exercise have been recommended for the treatment of this disease. Among these, exercise is known to be effective for the relief of symptoms of SUI; however, the efficacy and underlying mechanisms of the effect of exercise on SUI are poorly understood. We investigated the effect of swimming the symptom of SUI in relation to the expression of nerve growth factor (NGF) in rats.

Methods: Transabdominal urethrolysis was used to induce SUI, in Sprague-Dawley rats. The experimental groups were divided into the following three groups: sham-operation group, transabdominal urethrolysis-induced group, and transabdominal urethrolysis-induced and swimming group. The rats in the swimming group were forced to swim for 30 minutes once daily starting 2 weeks after SUI induction and continuing for 4 weeks. For this study, determination of abdominal leak point pressure and immunohistochemistry for NGF in the urethra and in the neuronal voiding centers (medial preoptic nucleus [MPA], ventrolateral periaqueductal gray [vlPAG], pontine micturition center [PMC], and spinal cord [L4-L5]) were performed.

Results: Transabdominal urethrolysis significantly reduced the abdominal leak point pressure, thereby contributing to the induction of SUI. Abdominal leak point pressure, however, was significantly improved by swimming. The expression of NGF in the urethra and in the neuronal voiding centers (MPA, vlPAG, PMC, and L4-L5) relating to micturition was enhanced by the induction of SUI. Swimming, however, significantly suppressed SUI-induced NGF expression.

Conclusions: Swimming alleviated symptoms of transabdominal urethrolysis-induced SUI, as assessed by an increase in abdominal leak point pressure. The underlying mechanisms of these effects of swimming might be ascribed to the inhibitory effect of swimming on NGF expression.
\end{abstract}

Keywords: Urinary incontinence; Swimming; Nerve growth factor; Rats

\section{INTRODUCTION}

Stress urinary incontinence (SUI) is the most common type of urinary incontinence. It causes the loss of small amounts of urine by coughing, laughing, sneezing, exercising, and other movements that increase intra-abdominal pressure and thus elevate pressure on the bladder. It is also associated with poor self-rated health, impaired quality of life, social isolation, and depressive symptoms [1]. Although the causes of SUI are multifactorial and the exact mechanisms of SUI are poorly under-
Corresponding author: Khae Hawn Kim

Department of Urology, Gachon University Gil Hospital, 191 Hambangmoe-ro, Namdong-gu, Incheon 405-760, Korea

Tel: +82-32-460-3331 / Fax: +82-32-460-8340

E-mail: kimcho99@gilhospital.com

Submitted: April 6, 2011 / Accepted after revision: May 10, 2011
This is an Open Access article distributed under the terms of the Creative Commons Attribution Non-Commercial License (http://creativecommons.org/licenses/by-nc/3.0/) which permits unrestricted non-commercial use, distribution, and reproduction in any medium, provided the original work is properly cited. 
stood, anatomical changes in urethral support and dysfunction of the intrinsic urethral sphincter partly contribute to involuntary urine loss during activities that cause abdominal straining $[2]$.

The ability of the lower urinary tract system to store and eliminate urine is controlled by a complex system of neural pathways in the central nervous system (CNS) and peripheral nervous system (PNS). Neuroanatomical tracing studies have indicated that the bladder and external urethral sphincter are innervated directly or indirectly from many CNS regions, including the pontine micturition center (PMC), locus coeruleus, hypothalamus, preoptic area, and spinal cord [3]. The PMC plays an important role in the control of urinary bladder function. The PMC is known as the supraspinal switching center, which regulates the storage and elimination of urine [4]. The PMC is densely innervated by the medial preoptic nucleus (MPA) [5]. Two regions that maintain direct projections to the PMC are the periaqueductal gray matter (PAG) and the MPA of the hypothalamus [6]. The PAG-PMC projection is thought to take part in the micturition reflex. Neurons in the PAG regulate the micturition reflex in both animals and humans, because lesions in the PAG cause severe urinary dysfunction $[7,8]$.

Nerve growth factor (NGF) is one of the neurotrophic factors needed for the maintenance of neuronal survival. NGF is produced by urothelium and smooth muscle cells [9]. Clinical and experimental data have indicated a direct relation of increased levels of NGF in bladder, urethral tissue, and urine with lower urinary tract disorders, such as overactive bladder symptoms, interstitial cystitis, urinary incontinence, and painful inflammatory condition $[10,11]$. Increased levels of NGF were also observed in the bladder and urethra of patients with sensory urgency and urinary incontinence [11,12].

Many therapeutic interventions, including pharmacologic agents and surgical treatments, have been attempted to cure SUI. However, some of the pharmacologic agents and surgical treatments cause many side effects [13]. Exercise of the pelvic muscle is known to increase muscle strength and to reduce incontinent urine loss. In addition, pelvic muscle exercise strengthens the muscles involved in the closing of the urethra during an increase in intra-abdominal pressure [14].

Water exercise including swimming is a common strategy in physical medicine and rehabilitation [15]. When exercising in water, buoyancy supports the body to reduce the vertical load on the joints, and the resistance created by the water requires subjects to exert greater force than when moving in air [16]. It was reported that water exercise improves pelvic muscle functions [17]; however, the effectiveness of water exercise for the relief of SUI symptoms and the underlying mechanisms of this effect are still unknown.

In the present study, we investigated the effects of swimming on SUI in relation to the expression of NGF in rats. We performed urodynamic testing to determine the abdominal leak point pressure and immunohistochemistry of NGF expression in the neuronal voiding centers (MPA, vlPAG, PMC, and spinal cord; L4-L5) and urethra following transabdominal urethrolysis in rats.

\section{MATERIALS AND METHODS}

\section{Animals}

Adult female Sprague-Dawley rats weighing $240 \pm 5 \mathrm{~g}$ (9 weeks old) were obtained from a commercial breeder (Orient Co., Seoul, Korea) for the experiment. The experimental procedures were performed in accordance with the animal care guidelines of the National Institutes of Health and the Korean Academy of Medical Sciences. The animals were housed under controlled temperature $\left(23 \pm 2^{\circ} \mathrm{C}\right)$ and lighting (12 hours of light: 0800 2000 hours) conditions and were supplied with food and water ad libitum before and after the surgery. The rats were randomly divided into three groups ( $\mathrm{n}=6$ in each group): the sham-operation group, the transabdominal urethrolysis-induced group, and the transabdominal urethrolysis-induced and swimming group.

\section{Surgical Induction of SUI}

To induce SUI, transabdominal urethrolysis was performed as previously described [2]. The rats were anesthetized with Zoletil 50 anesthesia (10 mg/kg, i.p.; Virbac Laboratories, Carros, France). After an abdominal incision was made, the bladder and the urethra were detached from surrounding tissues and nerves, and the urethra was detached from the anterior pubic bone. A cotton-tip swab was put into the vagina to aid with the dissection. In the sham operation group, an abdominal incision was made, but the urethra was not detached.

\section{Swimming Protocol}

The swimming exercise was performed according to the manufacturer's protocol [18]. The rats in the swimming group were forced to swim for 30 minutes once daily starting 2 weeks after SUI induction and continuing for 4 weeks. The rats individually 
swam in a cylindrical tank with a diameter of $30 \mathrm{~cm}$ and a height of $85 \mathrm{~cm}$. The cylindrical tank was filled with water at $33 \pm 1^{\circ} \mathrm{C}$ to a depth of $75 \mathrm{~cm}$.

\section{Determination of Abdominal Leak Point Pressure}

At 6 weeks after surgery, the abdominal leak point pressure was measured to assess urethral resistance according to a previously described method [19]. The rats were anesthetized with Zoletil 50 anesthesia $(10 \mathrm{mg} / \mathrm{kg}$, i.p.). All rats underwent T11 spinal cord transection to eliminate spontaneous bladder activity. After the abdominal incision was made, we inserted an intravesical catheter connected to a pressure transducer (Harvard Apparatus Inc., Holliston, MA, USA) in the dome of the bladder. We measured the abdominal leak point pressure by using a Labscribe (iWork System Inc., Dover, NH, USA).

All rats were mounted on a tilt table in a vertical position. Saline at room temperature was infused through the catheter and the maximal bladder capacity was determined when the first drop of urine appeared at the urethral meatus. The bladder was manually emptied by squeezing and was then filled to onethird capacity with saline. Then, the abdominal leak point pressure was determined as the peak bladder pressure inducing leakage of urine at the urethral meatus by use of manual abdominal compression. In this way, the abdominal leak point pressure was determined 10 times for each rat.

\section{Tissues Preparations}

The rats were sacrificed immediately after the measurement of abdominal leak point pressure. For the histological examination, urethral and bladder tissues were carefully dissected. The urethral tissues were fixed in optimal cutting temperature compound (Sakura Finetek Japan Co., Tokyo, Japan) and quickly frozen at $-70^{\circ} \mathrm{C}$ until analysis. Coronal sections of $10 \mu \mathrm{m}$ in thickness were made with a freezing microtome (Leica Biosystems Nussloch GmbH, Nussloch, Germany).

After tissues preparation of the urethral samples, the rats were transcardially perfused with $50 \mathrm{mM}$ phosphate-buffered saline, followed by $4 \%$ paraformaldehyde in $100 \mathrm{mM}$ sodium phosphate buffer at $\mathrm{pH}$ 7.4. The brain was removed, postfixed in the same fixative overnight, and transferred into a $30 \%$ sucrose solution for cryoprotection. Serial coronal sections $40 \mu \mathrm{m}$ thick were made with a freezing microtome. PMC was selected from the region spanning from Bregma -9.68 to $-9.80 \mathrm{~mm}$. vlPAG was selected from the region spanning from Bregma -7.64 to $-8.00 \mathrm{~mm}$, MPA was selected from the region spanning from
Bregma -0.26 to $0.80 \mathrm{~mm}$, and spinal cord was selected from the region spanning from L4-L5. Ten sections on average in each region were collected from each rat.

\section{NGF Immunohistochemistry}

Free-floating tissue sections were incubated overnight with mouse anti-NGF antibody (1:500; Santa Cruz Biotechnology Inc., Santa Cruz, CA, USA) and then with biotinylated mouse secondary antibody (1:200; Vector Laboratories Inc., Burlingame, CA, USA) for another 1 hour. The secondary antibody was amplified with the Vector Elite ABC kit (1:100; Vector Laboratories). Antibody-biotin-avidin-peroxidase complexes were visualized by use of $0.03 \%$ diaminobenzidine, and the sections were mounted onto gelatin-coated slides. The slides were airdried overnight at room temperature, and coverslips were mounted with Permount.

\section{Data Analysis}

To assess NGF expression in the neuronal voiding centers (MPA, vlPAG, PMC, and spinal cord L4-L5) and urethra, cell counting was performed by using the Image-Pro Plus computer-assisted image analysis system (Media Cybernetics Inc., Bethesda, MD, USA) attached to a light microscope (Olympus, Tokyo, Japan). The numbers of NGF-positive neurons were counted hemilaterally. Statistical analysis was performed by using one-way analysis of variance followed by Duncan's post-hoc test, and the results are expressed as the mean \pm standard error of the mean. Significance was set as $\mathrm{P}<0.05$.

\section{RESULTS}

\section{Effect of Swimming Exercise on Abdominal Leak Point Pressure}

The abdominal leak point pressure is presented in Fig. 1. The abdominal leak point pressure was $45.29 \pm 0.88 \mathrm{cmH}_{2} \mathrm{O}$ in the sham-operation group, $15.75 \pm 0.76 \mathrm{cmH}_{2} \mathrm{O}$ in the transabdominal urethrolysis-induced group, and $34.07 \pm 1.44 \mathrm{cmH}_{2} \mathrm{O}$ in the transabdominal urethrolysis-induced and swimming group.

These results showed that induction of SUI by transabdominal urethrolysis decreased the abdominal leak point pressure compared with that in the sham-operation group $(\mathrm{P}<0.05)$, whereas swimming increased the abdominal leak point pressure $(\mathrm{P}<0.05)$. 

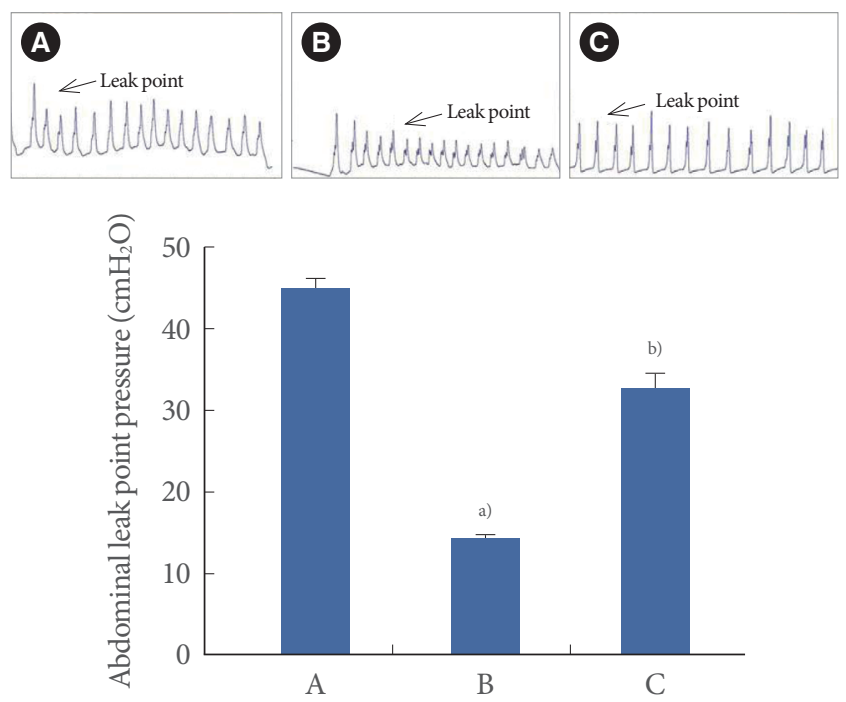

Fig. 1. Effect of swimming on abdominal leak point pressure after induction of stress urinary incontinence. Upper: Presentable trace of the abdominal leak point pressure. Lower: The mean abdominal leak point pressure in each group. (A) Sham-operation group, (B) Transabdominal urethrolysis-induced group, (C) Transabdominal urethrolysis-induced and swimming group. The results are presented as the mean \pm SEM. ${ }^{\text {a) }} \mathrm{P}<0.05$ compared with sham-operation group. ${ }^{\text {b) }} \mathrm{P}<0.05$ compared with transabdominal urethrolysis-induced group.

\section{Effect of Swimming on the Expression of NGF in the Urethra}

Photomicrographs of NGF-positive cells in the urethra are presented in Fig. 2. The number of NGF-positive cells was $9.46 \pm$ $1.77 / \mathrm{mm}^{2}$ in the sham-operation group, $33.07 \pm 6.43 / \mathrm{mm}^{2}$ in the transabdominal urethrolysis-induced group, and $23.78 \pm$ $4.63 / \mathrm{mm}^{2}$ in the transabdominal urethrolysis-induced and swimming group.

These results showed that induction of SUI by transabdominal urethrolysis increased the NGF expression in the urethra compared with that in the sham-operation group $(\mathrm{P}<0.05)$, whereas swimming suppressed the NGF expression in the urethra $(\mathrm{P}<0.05)$.

\section{Effect of Swimming on the Expression of NGF in the MPA}

Photomicrographs of NGF-positive cells in the MPA are presented in Fig. 3. The number of NGF-positive cells was $45.89 \pm$ $5.91 / \mathrm{mm}^{2}$ in the sham-operation group, $221.25 \pm 11.41 / \mathrm{mm}^{2}$ in the transabdominal urethrolysis-induced group, and $165.00 \pm$ $13.06 / \mathrm{mm}^{2}$ in the transabdominal urethrolysis-induced and swimming group.
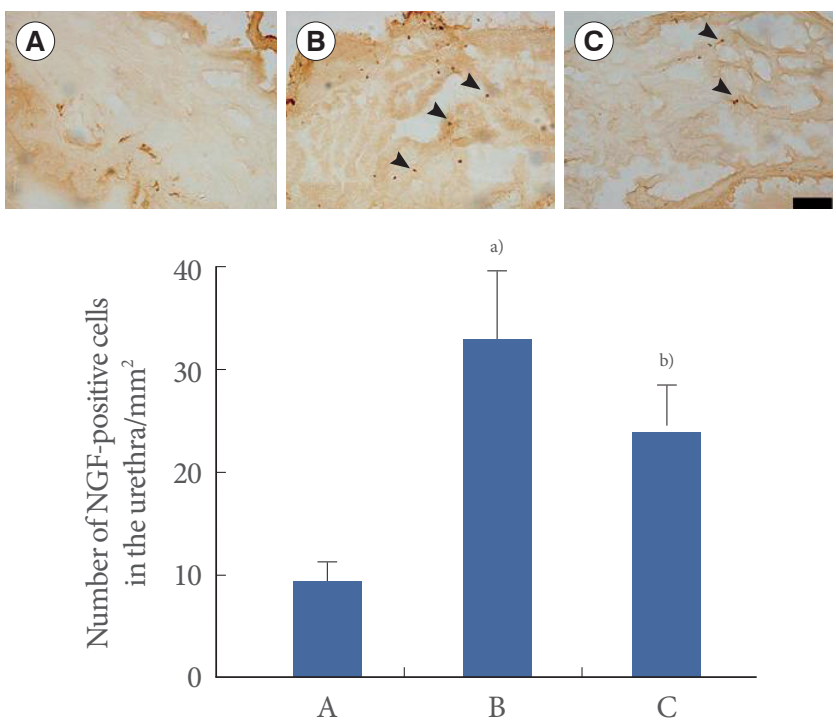

Fig. 2. Effect of swimming on nerve growth factor (NGF) expression in the urethra. Upper: Photomicrographs of NGF-positive cells in the urethra. The sections were stained for NGF-like immunoreactivity (brown). Arrows indicate NGF-positive cells. The scale bar represents $200 \mu \mathrm{m}$. Lower: The mean number of NGF-positive cells in each group. (A) Sham-operation group, (B) Transabdominal urethrolysis-induced group, (C) Transabdominal urethrolysis-induced and swimming group. The results are presented as the mean \pm SEM. ${ }^{a} \mathrm{P}<0.05$ compared with shamoperation group. ${ }^{\mathrm{b}} \mathrm{P}<0.05$ compared with transabdominal urethrolysis-induced group.

These results showed that induction of SUI by transabdominal urethrolysis increased the NGF expression in the MPA compared with that in the sham-operation group $(\mathrm{P}<0.05)$, whereas swimming exercise suppressed the NGF expression in the MPA $(\mathrm{P}<0.05)$.

\section{Effect of Swimming on the Expression of NGF in the vIPAG}

Photomicrographs of NGF-positive cells in the vlPAG are presented in Fig. 4. The number of NGF-positive cells was 111.35 \pm $15.27 / \mathrm{mm}^{2}$ in the sham-operation group, $579.61 \pm 37.17 / \mathrm{mm}^{2}$ in the transabdominal urethrolysis-induced group, and $372.40 \pm$ $29.63 / \mathrm{mm}^{2}$ in the transabdominal urethrolysis-induced and swimming group.

These results showed that induction of SUI by transabdominal urethrolysis increased the NGF expression in the vlPAG compared with that in the sham-operation group $(\mathrm{P}<0.05)$, whereas swimming suppressed the NGF expression in the vlPAG $(\mathrm{P}<0.05)$. 

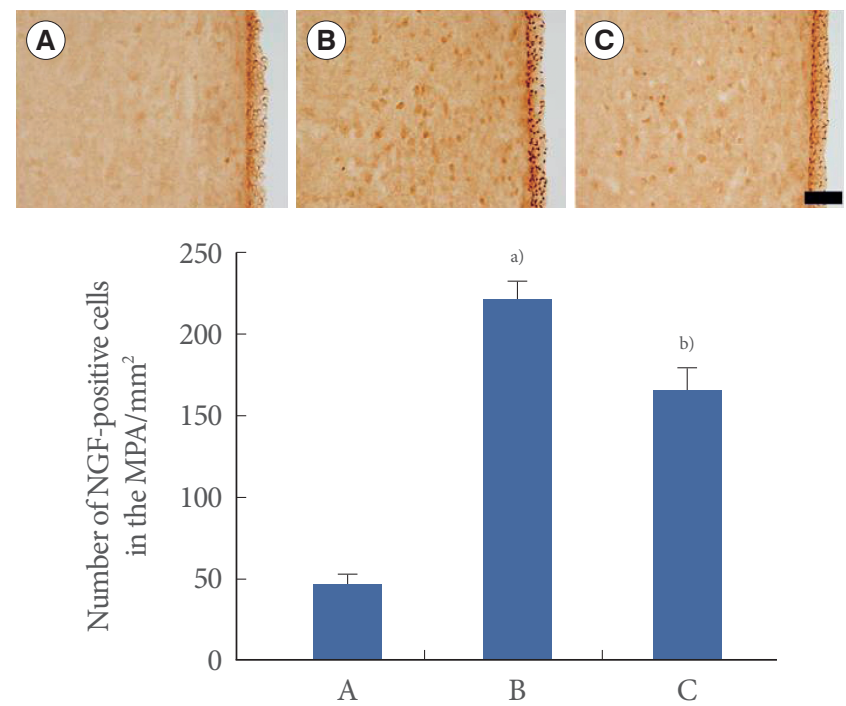

Fig. 3. Effect of swimming on nerve growth factor (NGF) expression in the medial preoptic nucleus (MPA). Upper: Photomicrographs of NGF-positive cells in the MPA. The sections were stained for NGF-like immunoreactivity (brown). The scale bar represents $200 \mu \mathrm{m}$. Lower: The mean number of NGF-positive cells in each group. (A) Sham-operation group, (B) Transabdominal urethrolysis-induced group, (C) Transabdominal urethrolysis-induced and swimming group. The results are presented as the mean \pm SEM. ${ }^{\text {a) }} \mathrm{P}<0.05$ compared with sham-operation group. ${ }^{b)} \mathrm{P}<0.05$ compared with transabdominal urethrolysis-induced group.

\section{Effect of Swimming on the Expression of NGF in the PMC}

Photomicrographs of NGF-positive cells in the PMC are presented in Fig. 5. The number of NGF-positive cells was $49.75 \pm$ $4.85 / \mathrm{mm}^{2}$ in the sham-operation group, $187.31 \pm 17.72 / \mathrm{mm}^{2}$ in the transabdominal urethrolysis-induced group, and 132.15 \pm $17.01 / \mathrm{mm}^{2}$ in the transabdominal urethrolysis-induced and swimming group.

These results showed that induction of SUI by transabdominal urethrolysis increased the NGF expression in the PMC compared with that in the sham-operation group $(\mathrm{P}<0.05)$, whereas swimming suppressed the NGF expression in the $\operatorname{PMC}(\mathrm{P}<0.05)$.

\section{Effect of Swimming Exercise on the Expression of NGF in the Spinal Cord (L4-L5)}

Photomicrographs of NGF-positive cells in the spinal cord are presented in Fig. 6. The number of NGF-positive cells was $26.35 \pm 4.60 / \mathrm{mm}^{2}$ in the sham-operation group, $71.30 \pm 11.85 /$ $\mathrm{mm}^{2}$ in the transabdominal urethrolysis-induced group, and $50.89 \pm 7.89 / \mathrm{mm}^{2}$ in the transabdominal urethrolysis-induced
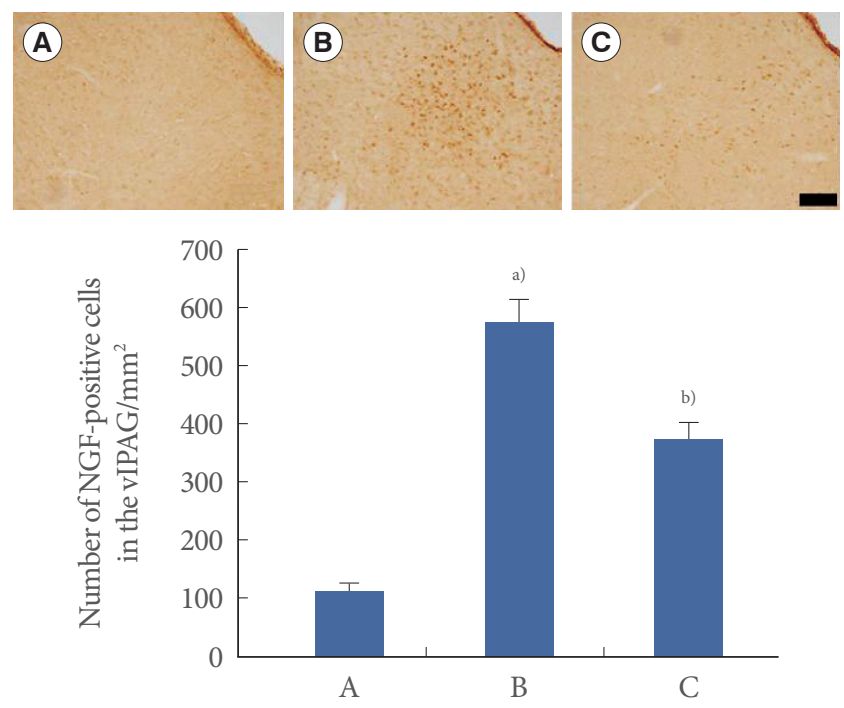

Fig. 4. Effect of swimming on nerve growth factor (NGF) expression in the ventrolateral periaqueductal gray matter (vlPAG). Upper: Photomicrographs of NGF-positive cells in the vlPAG. The sections were stained for NGF-like immunoreactivity (brown). The scale bar represents $200 \mu \mathrm{m}$. Lower: The mean number of NGF in each group. (A) Sham-operation group, (B) Transabdominal urethrolysis-induced group, (C) Transabdominal urethrolysis-induced and swimming group. The results are presented as the mean \pm SEM. ${ }^{\text {a) }} \mathrm{P}<0.05$ compared with shamoperation group. ${ }^{b} \mathrm{P}<0.05$ compared with transabdominal urethrolysis-induced group.

and swimming group.

These results showed that induction of SUI by transabdominal urethrolysis increased the NGF expression in the spinal cord compared with that in the sham-operation group $(\mathrm{P}<0.05)$, whereas swimming suppressed the NGF expression in the spinal cord $(\mathrm{P}<0.05)$.

\section{DISCUSSION}

Various animal models of SUI, such as inducing birth trauma by intravaginal balloon inflation and pudendal nerve crush, have been developed and used to evaluate the impact of experimental interventions for the treatment of SUI. However, these animal models are limited because of the low rate of incontinence, the difficulty of reproducibility, the high rate of bladder dysfunction, and the relatively short durability. On the other hand, transabdominal urethrolysis is a reliable and long-lasting method for inducing SUI compared with the existing models of SUI [2]. In addition to the induced structural changes, decreased urethral smooth muscle content, increased apoptosis, and a 

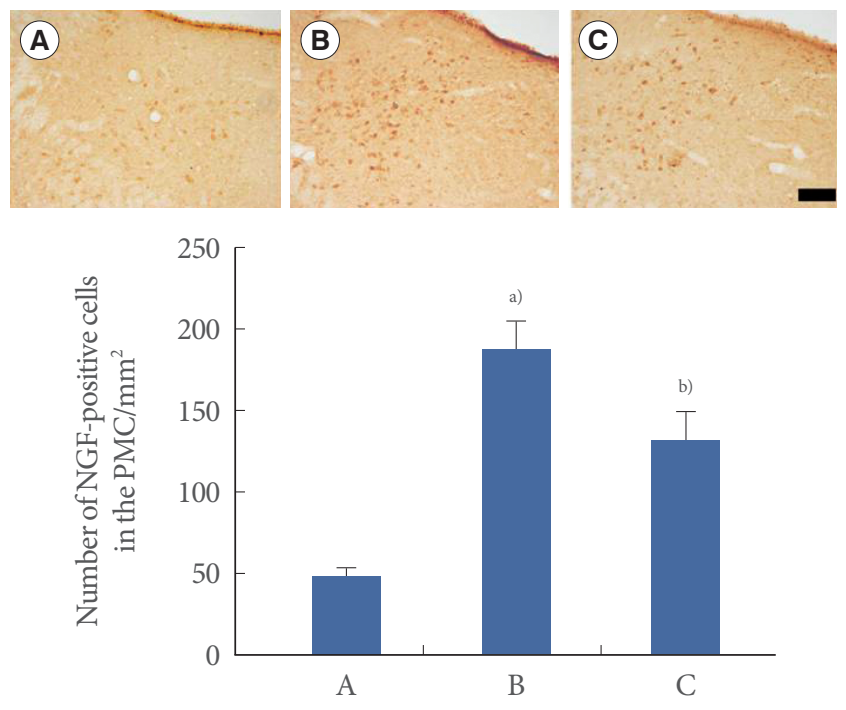

Fig. 5. Effect of swimming on nerve growth factor (NGF) expression in the pontine micturition center (PMC). Upper: Photomicrographs of NGF-positive cells in the PMC. The sections were stained for NGF-like immunoreactivity (brown). The scale bar represents $200 \mu \mathrm{m}$. Lower: The mean number of NGF-positive cells in each group. (A) Sham-operation group, (B) Transabdominal urethrolysis-induced group, (C) Transabdominal urethrolysis-induced and swimming group. The results are presented as the mean \pm SEM. ${ }^{\text {a) }} \mathrm{P}<0.05$ compared with sham-operation group. ${ }^{\text {b) }} \mathrm{P}<0.05$ compared with transabdominal urethrolysis-induced group.

time-dependent loss of neuronal content are observed with the transabdominal urethrolysis method [2]. In the present study, we measured the abdominal leak point pressure after transabdominal urethrolysis to confirm the induction of SUI.

The determination of abdominal leak point pressure is a useful surrogate for measuring the degree of sphincter insufficiency. Leak point pressure has been used as the candidate for the severity of incontinence, as a guideline for therapy, and in the evaluation of treatment outcomes [20,21]. The reflex activity of the bladder to the urethra contributes to the maintenance of a high leak point pressure during abdominal compression, and it increases passive intravesical pressure [22]. Abdominal leak point pressure has been measured in studies of SUI, and decreased abdominal leak point pressure is observed after the induction of SUI $[20,23,24]$. In the present study, the transabdominal urethrolysis procedure resulted in a decrease in abdominal leak point pressure. These results represent that transabdominal urethrolysis induced SUI in rats.

NGF content is elevated in the urine of patients with interstitial cystitis and with painful bladder contraction [25]. Overex-
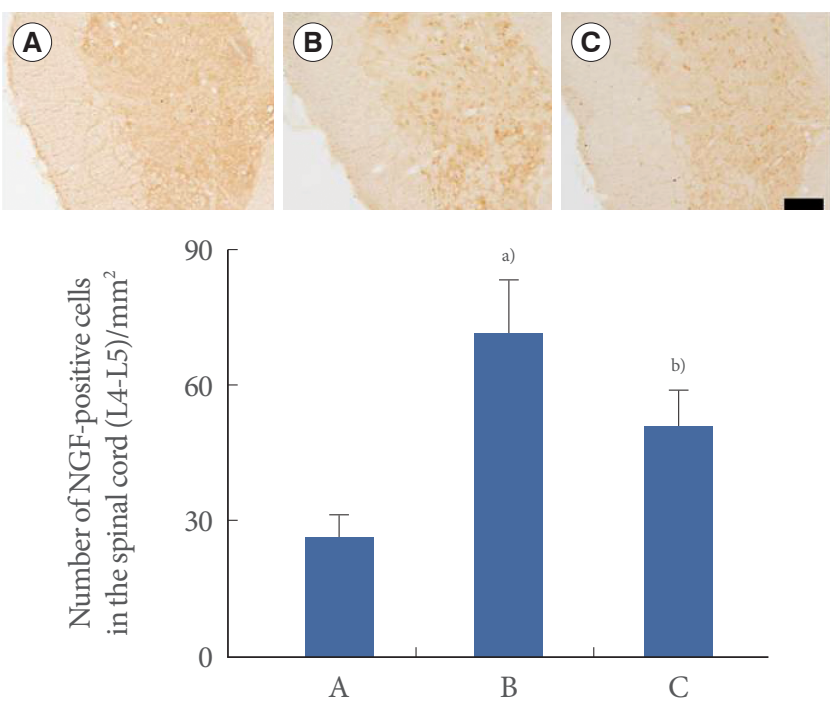

Fig. 6. Effect of swimming on nerve growth factor (NGF) expression in the spinal cord (L4-L5). Upper: Photomicrographs of NGF-positive cells in the spinal cord. The sections were stained for NGF-like immunoreactivity (brown). The scale bar represents $200 \mu \mathrm{m}$. Lower: The mean number of NGF-positive cells in each group. (A) Sham-operation group, (B) Transabdominal urethrolysis-induced group, (C) Transabdominal urethrolysis-induced and swimming group. The results are presented as the mean \pm SEM. ${ }^{\text {a) }} \mathrm{P}<0.05$ compared with sham-operation group. ${ }^{\text {b) }} \mathrm{P}<0.05$ compared with transabdominal urethrolysis-induced group.

pression of NGF in the bladder and urethra is associated with modulation disability of micturition in urinary incontinence patients [26,27]. Biochemical studies have suggested that NGF mediates afferent bladder neuronal plasticity after partial urethral obstruction in female rats [26,28]. Increased NGF levels in the bladder or bladder-afferent pathways may induce overactive bladder symptoms, incontinence, and c-fiber afferent hyperexcitability $[9,29]$. In the present study, transabdominal urethrolysis enhanced NGF expression in the urethra. These results show that transabdominal urethrolysis induced SUI with an increase in NGF expression in the urethra.

These changes in the bladder and urethra might stimulate the micturition-related brain area. Activation of PMC neurons initiates bladder contraction and relaxation of the bladder neck and external urethral sphincter, resulting in micturition [30]. The activated PMC in turn initiates complete synergic micturition responses via the excitation of parasympathetic bladder motor neurons in the sacral part of the spinal cord with the inhibition of the bladder sphincter motor neurons [6]. Thus, overexpression of NGF in the urethra and bladder may change the 
neuronal voiding centers in the brain.

Our present results showed that the expression of NGF in MPA, vlPAG, PMC, and spinal cord was significantly increased after transabdominal urethrolysis. The present results show that transabdominal urethrolysis increased the expression of NGF in the MPA, vlPAG, PMC, and spinal cord. It can be inferred that loss of supportive tissues or induction of smooth muscle atrophy by transabdominal urethrolysis might strongly stimulate the micturition-related neuronal voiding centers in the brain.

Swimming is a well-known exercise that facilitates recovery from functional loss after various diseases. In particular, swimming improves the disease-related functional decline in muscles, including muscle metabolism, protein synthesis, and mitochondrial biogenesis, in humans and animals [31-33]. It was reported that induction of neurotrophic factors, such as NGF, initiates changes in gene expression in muscles and brain during swimming adaptation [34]. Thus, it is possible that swimming could inhibit the overexpression of NGF induced by transabdominal urethrolysis.

In this study, we used urodynamic analysis to evaluate the effect of swimming on SUI-induced abdominal leak point pressure. Transabdominal urethrolysis significantly reduced the abdominal leak point pressure, thereby contributing to the induction of SUI. In contrast, abdominal leak point pressure was significantly improved by swimming. The present study showed that swimming alleviated the symptoms of SUI, as represented by the decrease in abdominal leak point pressure. In addition, swimming significantly suppressed the SUI-induced enhancement of NGF expression in the neuronal voiding centers (MPA, vIPAG, PMC, and spinal cord) and urethra. The results of the present study therefore suggest that the ameliorating effect of swimming on SUI might suppress NGF expression.

Strengthening of muscles and tissues by swimming may relieve the symptoms of SUI. One of the underlying mechanisms of the relieving effects of swimming on SUI might be ascribed to the inhibitory effect of swimming on NGF expression. We suggest that swimming is a valuable exercise for the remarkable improvement of SUI.

\section{CONFLICT OF INTEREST}

No potential conflict of interest relevant to this article was reported.

\section{ACKNOWLEDGEMENTS}

This work was supported by the National Research Foundation of Korea Grant funded by the Korean Government (20100003794).

\section{REFERENCES}

1. Saadoun K, Ringa V, Fritel X, Varnoux N, Zins M, Bréart G. Negative impact of urinary incontinence on quality of life, a cross-sectional study among women aged 49-61 years enrolled in the GAZEL cohort. Neurourol Urodyn 2006;25:696-702.

2. Rodríguez LV, Chen S, Jack GS, de Almeida F, Lee KW, Zhang R. New objective measures to quantify stress urinary incontinence in a novel durable animal model of intrinsic sphincter deficiency. Am J Physiol Regul Integr Comp Physiol 2005;288:R1332-8.

3. Rickey LM, Sarkey S, DonCarlos LL. Estrogen-sensitive projections from the medial preoptic area to the dorsal pontine tegmentum, including Barrington's nucleus, in the rat. Neurourol Urodyn 2008; 27:440-5.

4. Kavia RB, Dasgupta R, Fowler CJ. Functional imaging and the central control of the bladder. J Comp Neurol 2005;493:27-32.

5. Rizvi TA, Murphy AZ, Ennis M, Aston-Jones G, Shipley MT. Fos expression in rat pontine tegmental neurons following activation of the medial preoptic area. Brain Res 1998;789:256-62.

6. Blok BF, Holstege G. The pontine micturition center in rat receives direct lumbosacral input. An ultrastructural study. Neurosci Lett 2000;282:29-32.

7. Blok BF, Holstege G. Direct projections from the periaqueductal gray to the pontine micturition center (M-region). An anterograde and retrograde tracing study in the cat. Neurosci Lett 1994;166:93-6.

8. Sakakibara R, Hattori T, Yasuda K, Yamanishi T, Tojo M, Mori M. Micturitional disturbance in Wernicke's encephalopathy. Neurourol Urodyn 1997;16:111-5.

9. Steers WD, Tuttle JB. Mechanisms of disease: the role of nerve growth factor in the pathophysiology of bladder disorders. Nat Clin Pract Urol 2006;3:101-10.

10. Lowe EM, Anand P, Terenghi G, Williams-Chestnut RE, Sinicropi DV, Osborne JL. Increased nerve growth factor levels in the urinary bladder of women with idiopathic sensory urgency and interstitial cystitis. Br J Urol 1997;79:572-7.

11. Kuo HC, Liu HT, Chancellor MB. Urinary nerve growth factor is a better biomarker than detrusor wall thickness for the assessment of overactive bladder with incontinence. Neurourol Urodyn 2010;29: 482-7. 
12. Liu HT, Chen CY, Kuo HC. Urinary nerve growth factor levels in overactive bladder syndrome and lower urinary tract disorders. J Formos Med Assoc 2010;109:862-78.

13. Radley SC, Chapple CR, Bryan NP, Clarke DE, Craig DA. Effect of methoxamine on maximum urethral pressure in women with genuine stress incontinence: a placebo-controlled, double-blind crossover study. Neurourol Urodyn 2001;20:43-52.

14. Simon HB. On call. Muscle contraction controls urinary incontinence. Harv Mens Health Watch 2001;6:8.

15. Becker BE. Aquatic therapy: scientific foundations and clinical rehabilitation applications. PM R 2009;1:859-72.

16. Miyoshi T, Shirota T, Yamamoto S, Nakazawa K, Akai M. Effect of the walking speed to the lower limb joint angular displacements, joint moments and ground reaction forces during walking in water. Disabil Rehabil 2004;26:724-32.

17. Kaneda K, Sato D, Wakabayashi H, Nomura T. EMG activity of hip and trunk muscles during deep-water running. J Electromyogr Kinesiol 2009; 19:1064-70.

18. Lee HH, Kim H, Lee JW, Kim YS, Yang HY, Chang HK, et al. Maternal swimming during pregnancy enhances short-term memory and neurogenesis in the hippocampus of rat pups. Brain Dev 2006; 28:147-54.

19. Ko IG, Kim SE, Kim CJ, Jung JH, Lee SJ, Kim DH, et al. Effect of treadmill exercise on leak-point pressure and neuronal activation in brain of rats with stress urinary incontinence. Int Neurourol J 2010;14:141-8.

20. Conway DA, Kamo I, Yoshimura N, Chancellor MB, Cannon TW. Comparison of leak point pressure methods in an animal model of stress urinary incontinence. Int Urogynecol J Pelvic Floor Dysfunct 2005;16:359-63.

21. Cannon TW, Sweeney DD, Conway DA, Kamo I, Yoshimura N, Sacks M, et al. A tissue-engineered suburethral sling in an animal model of stress urinary incontinence. BJU Int 2005;96:664-9.

22. Kamo I, Cannon TW, Conway DA, Torimoto K, Chancellor MB, de Groat WC, et al. The role of bladder-to-urethral reflexes in urinary continence mechanisms in rats. Am J Physiol Renal Physiol 2004;287:F434-41.

23. Phull H, Salkini M, Escobar C, Purves T, Comiter CV. The role of angiotensin II in stress urinary incontinence: a rat model. Neurourol Urodyn 2007;26:81-8.
24. Kwon D, Kim Y, Pruchnic R, Jankowski R, Usiene I, de Miguel F, et al. Periurethral cellular injection: comparison of muscle-derived progenitor cells and fibroblasts with regard to efficacy and tissue contractility in an animal model of stress urinary incontinence. Urology 2006;68:449-54.

25. Okragly AJ, Niles AL, Saban R, Schmidt D, Hoffman RL, Warner TF, et al. Elevated tryptase, nerve growth factor, neurotrophin-3 and glial cell line-derived neurotrophic factor levels in the urine of interstitial cystitis and bladder cancer patients. J Urol 1999;161:438-41.

26. Furuta A, Kita M, Suzuki Y, Egawa S, Chancellor MB, de Groat WC, et al. Association of overactive bladder and stress urinary incontinence in rats with pudendal nerve ligation injury. Am J Physiol Regul Integr Comp Physiol 2008;294:R1510-6.

27. Schnegelsberg B, Sun TT, Cain G, Bhattacharya A, Nunn PA, Ford AP, et al. Overexpression of NGF in mouse urothelium leads to neuronal hyperinnervation, pelvic sensitivity, and changes in urinary bladder function. Am J Physiol Regul Integr Comp Physiol 2010;298:R534-47.

28. Steers WD, Kolbeck S, Creedon D, Tuttle JB. Nerve growth factor in the urinary bladder of the adult regulates neuronal form and function. J Clin Invest 1991;88:1709-15.

29. Zettler C, Bridges DC, Zhou XF, Rush RA. Detection of increased tissue concentrations of nerve growth factor with an improved extraction procedure. J Neurosci Res 1996;46:581-94.

30. Andersson KE, Wein AJ. Pharmacology of the lower urinary tract: basis for current and future treatments of urinary incontinence. Pharmacol Rev 2004;56:581-631.

31. Tipton KD, Ferrando AA, Williams BD, Wolfe RR. Muscle protein metabolism in female swimmers after a combination of resistance and endurance exercise. J Appl Physiol 1996;81:2034-8.

32. Garcia-Roves PM, Huss J, Holloszy JO. Role of calcineurin in exercise-induced mitochondrial biogenesis. Am J Physiol Endocrinol Metab 2006;290:E1172-9.

33. Oh KS, Kim EY, Yoon M, Lee CM. Swim training improves leptin receptor deficiency-induced obesity and lipid disorder by activating uncoupling proteins. Exp Mol Med 2007;39:385-94.

34. Radak Z, Toldy A, Szabo Z, Siamilis S, Nyakas C, Silye G, et al. The effects of training and detraining on memory, neurotrophins and oxidative stress markers in rat brain. Neurochem Int 2006;49:387-92. 